\title{
INDICADORES DE REJEIÇÃO EM GRUPO DE CRIANÇAS
}

\author{
INDICATORS OF REJECTION IN GROUPS OF CHILDREN
}

\author{
Vera Regina Miranda Gomes da Silva ${ }^{1}$ \\ Suzane Schmidlin Löhr
}

\begin{abstract}
RESUMO
O tema rejeição vem motivando inúmeros pesquisadores, devido à íntima relação entre a rejeição dos pares e dificuldades de ajustamento futuro. Estudar tal tema pode contribuir para a detecção de fatores desencadeadores de rejeição, propiciando em decorrência, intervenções preventivas. O texto pretende resumir a pesquisa de mestrado da autora em que se objetivou detectar os indicadores de rejeição entre crianças de $4^{\text {a }}$ série de uma escola particular de Curitiba ( $n=52)$. Entende-se, no presente estudo, "indicadores de rejeição" como critérios que levam crianças a excluírem umas às outras de suas atividades de jogo e de trabalho, dentro do contexto escolar. No estudo foram utilizados instrumentos dirigidos à coleta de dados junto às crianças ("votação às avessas" e "passa a bola") e outro visando à obtenção de dados por parte dos professores ("ficha do professor"). A análise e o cruzamento dos dados obtidos permitiram constatar que as crianças tendem a rejeitar os seus pares com base em comportamentos inadequados emitidos por estes (autoritarismo, conduta perturbadora), percepção esta, reforçada pelos dados obtidos dos professores. Em contrapartida, as crianças tendem a escolher seus pares devido à emissão, em alta freqüência, de comportamentos pró-sociais por parte destes.
\end{abstract}

Palavras-chave: rejeição, crianças rejeitadas, rejeição entre pares, reconhecimento da rejeição.

\begin{abstract}
The issue of rejection is motivating countless researchers due to the close relationship between peer rejection and difficulties in future adjustment. The study of this issue can contribute towards the detection of factors that trigger rejection, consequently making possible preventive interventions. This text is intended to provide a summary of the research undertaken by the author as part of her Master's Degree, the aim of which was to detect indicators of rejection in the final year of a private primary school in Curitiba $(n=52)$. In this study, "indicators of rejection" are understood to be criteria that lead children to exclude each other from their recreation and working activities, within the context of the school. The study used one instrument designed to collect data from the children ("voting for the least popular" and "tag") and another aimed at obtaining data from the teachers ("teacher's card"). The analysis and cross-referencing of the data obtained indicated that children tend to reject their peers based on their inadequate behaviour (bossiness, disruptive behaviour), and this perception was reinforced by the data obtained from the teachers. On the other hand, children tend to chose other children who frequently demonstrate sociable behaviour to be their peers.
\end{abstract}

Keywords: Rejection, rejected children, peer rejection, recognition of rejection.

\section{INTRODUÇÃO}

Os problemas sociais comumente referem-se às relações entre as pessoas, envolvendo dificuldades de comunicação, integração e cooperação. A maior parte dos seres humanos deseja ser escolhida e aceita pelos outros, fazer parte de grupos sociais e sabe-se que indivíduos que são aceitos e que se aceitam têm maior probabilidade de virem a aceitar e respeitar os outros (Argyle,

\footnotetext{
${ }^{1}$ Psicóloga clínica e escolar. Mestre em psicologia da infância e da adolescência pela UFPR, Professora dos cursos de Psicologia da PUC/PR, da UNICENP e UTP. E-mail: veramirandagomes@onda.com.br.

2 Psicóloga clínica. Doutora em psicologia pela USP. Professora de psicologia da graduação e pós-graduação da UFPR. Coordenadora do curso de psicologia da UNICENP. E-mail: lohr@ palm.com.br.
} 
1976 e Briggs, 1995). Em suma, toda criança anseia profundamente ser incluída. Não ser aceito pelos grupos é um fenômeno que a comunidade tende a denominar de "REJEIÇÃO", e que gera muitas dificuldades aos indivíduos alvo da mesma. Inúmeros são os estudos que, direta ou indiretamente, abordam a rejeição entre os pares (Gottman, Gonso \& Rasmussen, 1975; Ames, Ames \& Garrison, 1977; Peery, 1979; Masters \& Furman, 1981; Putallaz \& Gottman, 1981; Coie, Dodge \& Coppotelli, 1982; Vosk, Forehand, Parker \& Richard, 1982; Dodge, 1983; Dodge, Schlundt, Schoken \& Delugach, 1983; Putallaz, 1983; Hartrup \& Rubin, 1986; Putallaz \& Wasserman, 1989; Price \& Dodge, 1989; Rubin, 1990; Coie, Dodge \& Kupersmidt, 1995; Coie \& Koeppl, 1995; Cassidy, Kirsh, Scolton \& Parke, 1996.

Identificar crianças que persistem em padrões comportamentais desadaptativos pode ser importante diagnóstico para investigar habilidades sociais e capacitá-las a prevenir possíveis rejeições, conforme defendem Asher e Coie (1995).

Conforme exposto anteriormente, as conseqüências da rejeição para o desenvolvimento psicológico de crianças e adultos motiva pesquisadores a empreenderem estudos sobre comportamentos inapropriados que geram rejeição, bem como a buscar as habilidades pró-sociais requisitadas a uma boa inter-relação e que contribuem para a prevenção da saúde mental.

Considerando as implicações da exclusão por parte dos pares no desenvolvimento emocional das crianças, assim como os dados relativos a características do rejeitado que possam favorecer a rejeição, estrutura-se o presente estudo, que objetiva detectar critérios que levam crianças a rejeitarem seus pares, dentro do contexto escolar.

\section{MÉTODO}

\section{PARTICIPANTES/CONTEXTO}

A amostra abrangeu de 52 estudantes, de ambos os sexos, de uma escola particular de Curitiba, com idade média de 10 anos, cursando a $4^{\mathrm{a}}$ série (das turmas $\mathrm{A}$ e $\mathrm{B}$ ), pertencentes a um nível socioeconômico médio, e de raça branca.

O contexto escolhido foi a escola, visto ela representar o lugar onde a criança desenvolverá relações com pares, passando a ocupar posição no grupo, defrontando-se com as semelhanças e as diferenças individuais, em diversos aspectos, o que pode levar ao pertencimento ou à rejeição frente ao grupo.

O critério adotado consistiu em incluir todos os alunos matriculados nesta série, das duas turmas existentes na escola.

\section{MATERIAL}

Os instrumentos descritos foram utilizados para a obtenção dos dados do presente estudo.

\subsection{Votação às avessas}

As crianças receberam instrução para votarem, devendo registrar numa "cédula eleitoral", quem não escolheriam para jogar e para fazer trabalho em grupo e fornecer as justificativas para as suas respostas. Os objetivos deste instrumento foram: a) detectar as crianças menos escolhidas pelo grupo; b) levantar as justificativas (critérios) para as suas rejeições.

\subsection{Ficha do Professor}

Os professores preencheram ficha sobre comportamentos apresentados pelos seus alunos, individualmente. Os objetivos desta avaliação foram: a) verificar percepções de cada professor sobre características individuais de crianças que sejam passíveis de rejeição entre seus pares; b) comparar crianças menos escolhidas, suas características segundo os professores; c) detectar o grau de concordância entre alunos e professores.

\subsection{Passa a bola}

As crianças formaram um círculo e deveriam jogar a bola para outra criança do mesmo círculo. Ao jogar a bola verbalizaram um atributo positivo para aquela que selecionaram para receber a bola. Os objetivos deste instrumento foram: a) verificar quais as crianças menos escolhidas pelo grupo através de um recurso não-verbal; b) comparar se as rejeições são as mesmas detectadas na "votação às avessas"; c) detectar critérios de escolha através dos atributos 
verbais que forem apresentados; d) comparar se os critérios de escolha são opostos aos critérios de rejeição listados anteriormente.

\section{PROCEDIMENTOS}

Antes de iniciar a aplicação dos procedimentos, as crianças levaram uma comunicação aos pais a fim de esclarecer sobre o projeto de pesquisa e solicitar autorização para a sua participação.

apresentado.

Os procedimentos utilizados seguiram a seqüência descrita no esquema abaixo 


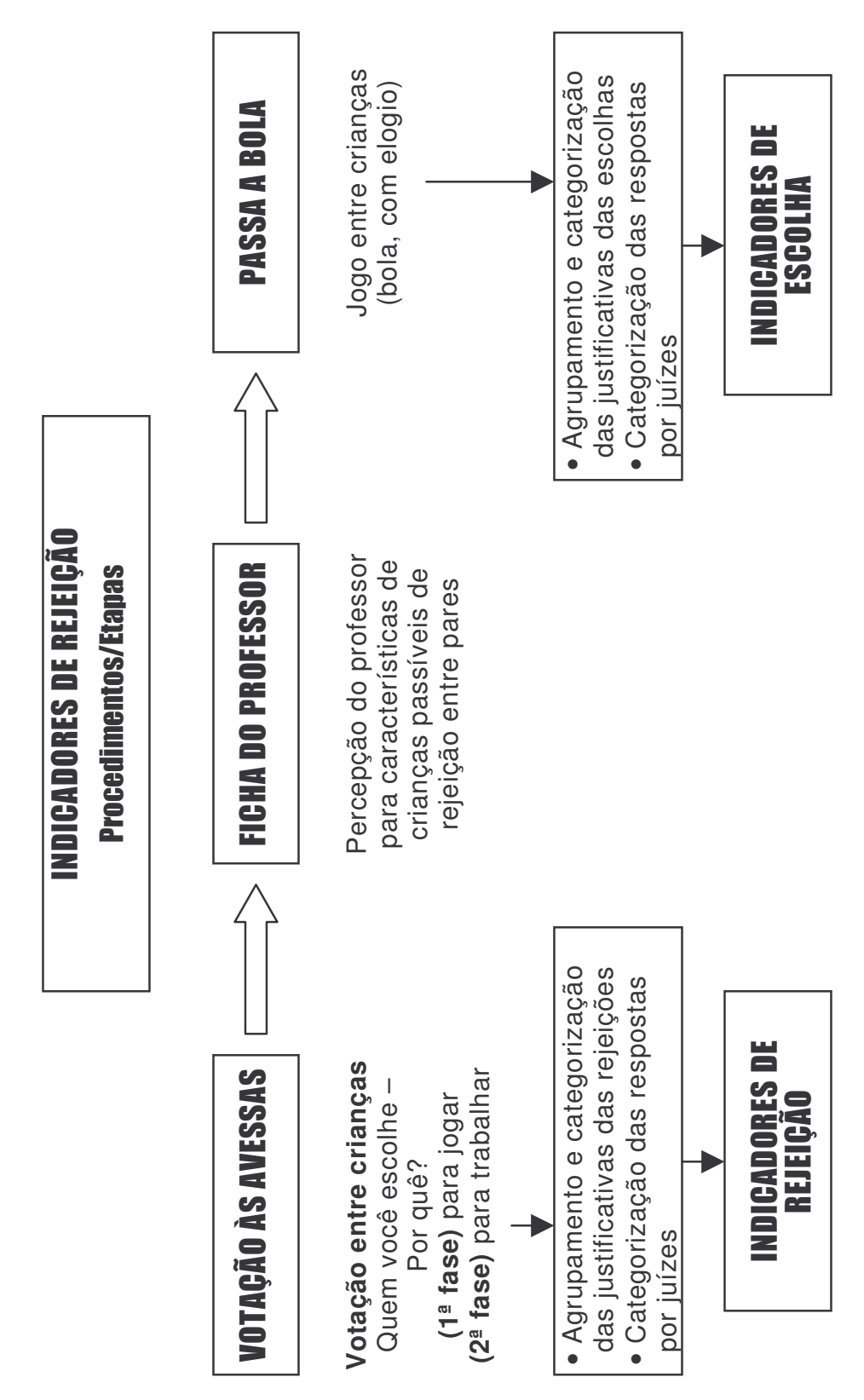


Conforme pode observar-se no esquema, tanto as justificativas para as não-escolhas quanto as justificativas para as escolhas foram categorizadas após terem sido submetidas à apreciação de oito juízes que se posicionaram frente aos possíveis nomes das categorias e às condutas a elas correspondentes. À categorização decorrente da "votação às avessas" denominou-se indicadores de rejeição (para jogar e trabalhar), enquanto a decorrente do "passa a bola" denominou-se indicadores de escolha. professor.

As categorias extraídas da "votação às avessas" subsidiaram a construção da ficha do

\section{RESULTADOS E DISCUSSÃO}

Para a análise dos objetivos levantados no trabalho foram utilizados os testes nãoparamétricos "Comparação entre duas Proporções" (através do software "Primer of Biostatistics"), "Qui-Quadrado com correção de Yates" e "Exato de Fisher" (pelo software "EpiInfo") para amostras independentes.

O nível de significância (ou probabilidade de significância) mínimo adotado foi de 5\%.

O estudo estatístico prévio concluiu não serem significativas as diferenças entre as turmas $A$ e $B$, por isto apresentam-se apenas alguns dos resultados referentes ao total geral, integrando aos duas turmas.

\section{VOTAÇÃO ÀS AVESSAS}

O Quadro 1 visualiza as oito categorias de rejeição, seguidas de suas respectivas definições operacionais e das justificativas fornecidas pelas crianças. 


\begin{tabular}{|c|c|c|}
\hline $\begin{array}{l}\text { CATEGORIAS } \\
\text { DE REJEIÇÃO }\end{array}$ & $\begin{array}{c}\text { DEFINIÇÕES } \\
\text { OPERACIONAIS }\end{array}$ & $\begin{array}{l}\text { JUSTIFICATIVAS } \\
\text { (respostas fornecidas } \\
\text { pelas crianças) }\end{array}$ \\
\hline Autoritário & $\begin{array}{l}\text { Postura "ditatorial" na } \\
\text { relação com os demais }\end{array}$ & $\begin{array}{l}\text { Metido, mandão, } \\
\text { exibido, dá ordens, } \\
\text { julga-se o melhor, o } \\
\text { único que sabe. }\end{array}$ \\
\hline Perturbador & $\begin{array}{l}\text { Condutas que } \\
\text { incomodam o ambiente, } \\
\text { incluindo agitação, } \\
\text { irritabilidade e } \\
\text { pessimismo }\end{array}$ & $\begin{array}{l}\text { Faz bagunça, brinca } \\
\text { muito, conversa muito, } \\
\text { nervoso, reclamão, } \\
\text { provocativo, chato, } \\
\text { incomoda, perturba. }\end{array}$ \\
\hline Não-Participativo & $\begin{array}{l}\text { Omissão à participação } \\
\text { em atos e idéias }\end{array}$ & $\begin{array}{l}\text { Não brinca, não joga, } \\
\text { não trabalha, não faz } \\
\text { nada, não dá idéias. }\end{array}$ \\
\hline Agressivo & $\begin{array}{l}\text { Agressividade em atos } \\
\text { e palavras. }\end{array}$ & $\begin{array}{l}\text { Briga, xinga, diz } \\
\text { palavrões, bate, } \\
\text { empurra. }\end{array}$ \\
\hline Transgressor & $\begin{array}{l}\text { Desrespeito a normas, } \\
\text { regras e combinados }\end{array}$ & $\begin{array}{l}\text { Promete e não cumpre, } \\
\text { dá o cano, não respeita } \\
\text { regras. }\end{array}$ \\
\hline Não-Amigo & $\begin{array}{l}\text { Atitudes de } \\
\text { egocentrismo e } \\
\text { ausência de afetividade, } \\
\text { afinidade e convivência } \\
\text { em relação às pessoas. }\end{array}$ & $\begin{array}{l}\text { Não empresta suas } \\
\text { coisas, não é meu } \\
\text { amigo, não gosta de } \\
\text { mim, fala mal dos } \\
\text { outros. }\end{array}$ \\
\hline $\begin{array}{l}\text { Inábil Acadêmico } \\
\text { e/ou Motor }\end{array}$ & $\begin{array}{l}\text { Carência de habilidades } \\
\text { cognitivas e } \\
\text { acadêmicas que } \\
\text { envolvem dificuldades } \\
\text { de memória, } \\
\text { motricidade, atenção, } \\
\text { inteligência, ritmo de } \\
\text { reação. }\end{array}$ & $\begin{array}{l}\text { Letra feia; não capricha; } \\
\text { lento; idéias absurdas; } \\
\text { esquecido; desligado; } \\
\text { não sabe: jogar, chutar, } \\
\text { brincar; corre pouco. }\end{array}$ \\
\hline Estigmatizado & $\begin{array}{l}\text { Características alvo de } \\
\text { possíveis estigmas, } \\
\text { relativas à aparência, } \\
\text { problemas físicos e não } \\
\text { esclarecimentos para } \\
\text { exclusão. }\end{array}$ & $\begin{array}{l}\text { Gordo, deficiente físico, } \\
\text { tem problemas, prefiro o } \\
\text { mesmo sexo, não gosto } \\
\text { dele. }\end{array}$ \\
\hline
\end{tabular}

Quadro 1: Definição dos Indicadores de Rejeição

A Tabela 1 compara as rejeições para jogar e trabalhar, referenciando a criança em relação ao seu próprio sexo e ao sexo oposto.

Tabela 1 - Rejeição para jogar e para trabalhar em relação ao próprio sexo e ao sexo oposto - total geral

\begin{tabular}{l|rr|r|r|r|r}
\hline \multirow{2}{*}{ REJEIÇÃO } & \multicolumn{2}{|c|}{ MASCULINO } & \multicolumn{2}{c|}{ FEMININO } & \multicolumn{2}{|c}{ TOTAL } \\
\cline { 2 - 8 } & \multicolumn{1}{c}{ № } & \multicolumn{1}{c}{ № } & \multicolumn{1}{c}{$\%$} & \multicolumn{1}{c}{ № } & $\%$ \\
\hline JOGAR & 66 & 100,0 & 60 & 100,0 & 126 & 100,0 \\
- Masculino & 42 & 63,6 & 07 & 11,7 & 49 & 38,9 \\
- Feminino & 24 & 36,4 & 53 & 88,3 & 77 & 61,1 \\
& & & & & & \\
TRABALHAR & 62 & 100,0 & 63 & 100,0 & 125 & 100,0 \\
- Masculino & 37 & 59,7 & 14 & 22,2 & 51 & 40,8 \\
- Feminino & 25 & 40,3 & 49 & 77,8 & 74 & 59,2
\end{tabular}


Observando a tabela, conclui-se que, de modo geral, as meninas rejeitam tanto para jogar $(88,3 \%)(p<0,00001)$ como para trabalhar $(77,8 \%)(p=0,00004)$ as próprias meninas, tendo mais inclinação à rejeição pelo mesmo sexo que os meninos, que o fazem em $63,6 \%$ para jogar e 59,7\% para trabalhar.

A Figura 1 demonstra a rejeição para jogar e trabalhar entre as crianças, considerando o total acumulado nos dois sexos.

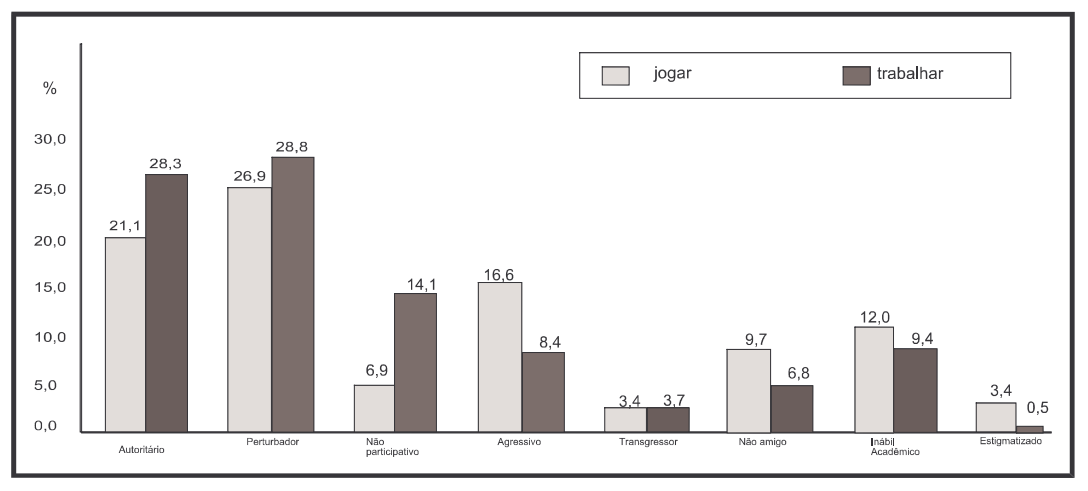

Figura 1: Rejeição para jogar e trabalhar, entre as crianças - total geral (autoritário, perturbador, não participativo, agressivo, transgressor, não amigo, inábil acadêmico, estigmatizado).

Percebe-se que para jogar e trabalhar rejeitam-se crianças, principalmente, que evidenciam comportamentos enquadrados nas categorias "autoritário" (21,1\% para jogar, $28,3 \%$ para trabalhar) e "perturbador" (26,9\% para jogar e $28,8 \%$ para trabalhar).

Para atividades envolvendo trabalho grupal, a porcentagem de rejeição para o "nãoparticipativo" é maior $(14,1 \%)$ do que para jogar $(6,9 \%)$, possivelmente porque fazer trabalho em grupo, tem conotação acadêmica e o desempenho será certamente quantificado pelo professor, posteriormente. Condutas "agressivas" são mais rejeitadas para jogar $(16,6 \%)$ do que para trabalhar (8,4\%), assim como a categoria "não-amigo" é alvo de maior rejeição no jogo $(9,7 \%)$ do que no trabalho $(6,8 \%)$.

Coie e Koppel (1995) fazem menção ao comportamento disruptivo e sua relação com a rejeição entre os pares e, pode-se aqui fazer analogia entre a categoria perturbador e o comportamento disruptivo, embora a literatura não seja suficientemente explícita para operacionalizar o termo "disruptivo".

A categoria "autoritário" obtém segunda posição de destaque nas rejeições $(28,3 \%$ para trabalhar e 21,1\% para jogar) e, segundo Adorno et al. (1965), e Coie e Koeppl (1995), as crianças controladoras e dominadoras gastam muita energia na manutenção do seu status e do controle, não são tão divertidas nos relacionamentos, agem de modo autocentrado e não influenciam seus pares de modo aceitável. Coie e Koeppl (1995) concluem que crianças rejeitadas são mais disruptivas e agressivas e menos efetivas com seus pares, já que dispendem grande energia com contatos aversivos.

Evidencia-se, deste modo, que os indicadores de rejeição podem ser agrupados em categorias e associam-se muito mais a comportamentos inapropriados emitidos pela criança alvo da exclusão, o que coincide com dados da literatura. Price e Dodge (1989) afirmam que o grau em que as crianças são aceitas ou rejeitadas pelos membros de seus grupos depende em parte da qualidade de seu comportamento nas interações com os pares. 
Realizando análise individual das crianças que obtiveram escores mais elevados de rejeição para jogar e/ou trabalhar constatou-se que, das 23 crianças mais rejeitadas, 9 são do sexo feminino $(39,13 \%)$ e 14 do sexo masculino $(60,86 \%)$. Há pelo menos uma categoria comum entre 21 dos casos apresentados (91,3\%) e em 14 há 2 ou mais categorias comuns $(60,86 \%)$, o que revela que os sujeitos rejeitados o são, em mais de uma categoria.

\section{FICHA DO PROFESSOR}

A Figura 2 demonstra a percepção dos professores sobre as crianças, avaliando a conduta das mesmas dentro do contexto escolar.

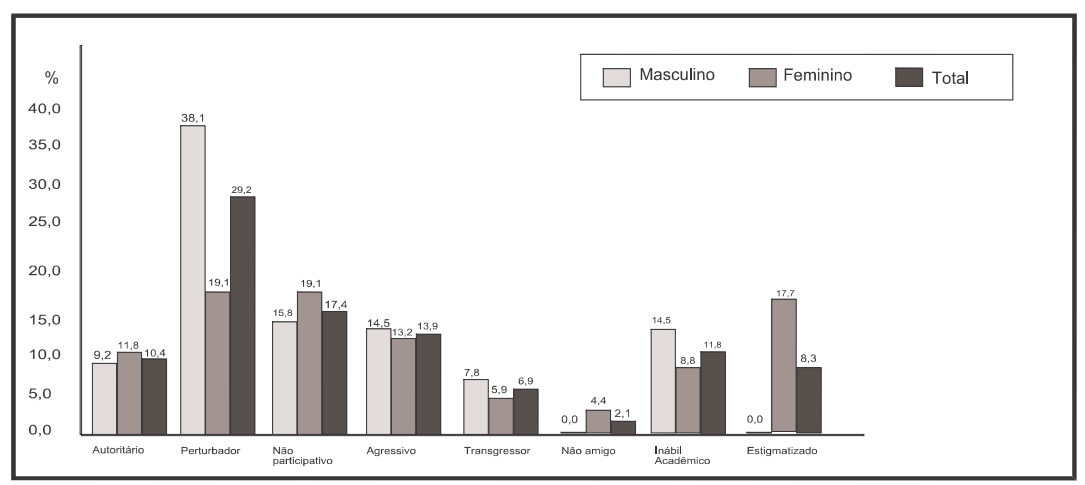

Figura 2: Rejeição para trabalhar, por sexo, segundo percepção do professor (autoritário, perturbador, não participativo, agressivo, transgressor, não amigo, inábil acadêmico, estigmatizado).

Os professores relatam perceber que crianças rejeitadas pelo grupo, quando do sexo masculino, apresentam comportamentos agrupados na categoria "perturbador" (38,1\%), seguido da categoria "não-participativo" (15,8\%). Já, quanto ao sexo feminino, as categorias de maior incidência para a rejeição são pertencentes às designações "perturbador" e "não participativo", ambas com percentual de $19,1 \%$.

Os achados do estudo refletem dados da literatura, em que as crianças com condutas externalizantes tendem a ser mais observadas pelos professores devido ao fato de perturbarem o ambiente (Ross, 1974). São também estas condutas as que mais suscitam encaminhamentos para intervenção, conforme levantamento de Gomes da Silva e Sternadt (1999) em escolas da região de Curitiba. Marturano, Linhares e Parreira (1993) relatam que estas mesmas características, (agitação e comportamento externalizado) são detectadas em crianças encaminhadas para atendimento.

A Figura 3 integra a comparação entre a percepção dos professores (detectada pela ficha do professor) e das crianças (detectada pela votação às avessas) quanto à rejeição para trabalhar. 


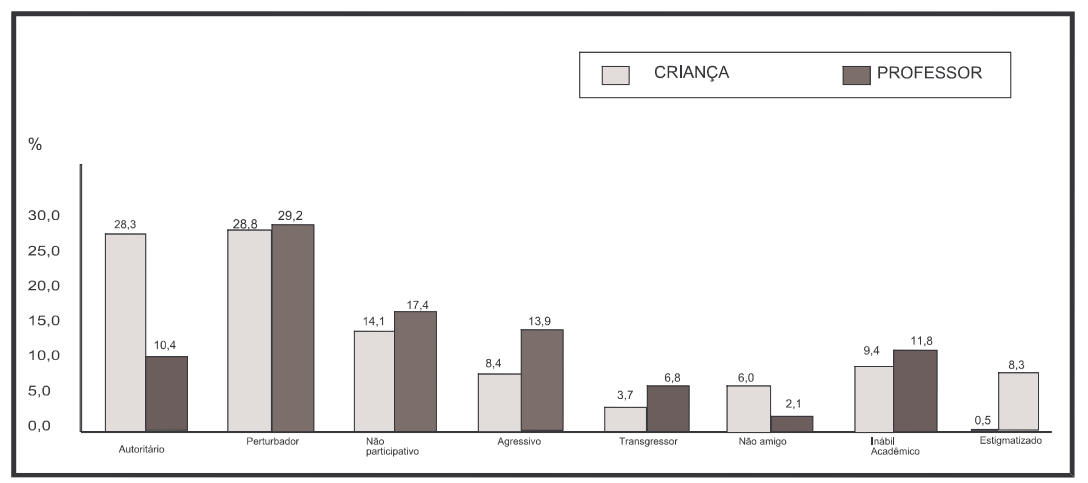

Figura 3: Comparação entre a percepção dos professores e das crianças quanto à rejeição para trabalhar (autoritário, perturbador, não participativo, agressivo, transgressor, não amigo, inábil acadêmico, estigmatizado).

Ao observar-se a Figura 3, evidencia-se que crianças e professores consideram a categoria "perturbador" como a mais relacionada com a rejeição na realização de trabalhos acadêmicos grupais, inclusive com percentuais muito aproximados (28,8\% para crianças e $29,2 \%$ para professores), evidenciando ser esta categoria um forte indicador de rejeição entre crianças. No entanto, professores percebem a estigmatização muito mais do que as próprias crianças.

\subsection{Comparação entre a ficha do professor e a votação às avessas}

A comparação entre estes dois instrumentos permite observar que as crianças rejeitam seus pares que apresentam comportamentos perturbadores $(28,8 \%)$, e os professores percebem que as crianças com estas categorias $(23,2 \%)$ são as que mais geram rejeição por parte dos seus iguais.

A conduta autoritária incomoda muito mais as crianças $(28,3 \%)$ do que a que é percebida pelos professores $(10,4 \%)$ como inapropriada no contexto acadêmico. Pode-se levantar a hipótese de que entre os pares, que sentem-se em igual poder hierárquico, a conduta ditatorial tende a ser vista como inaceitável, pois se pressupõe que todos desfrutam de igual status. Condutas classificadas como "mandão", "exibido", que dá ordens, que julga que "tudo sabe", podem não ser bem-vindas, uma vez que conduzem à supremacia de um membro do grupo sobre os demais.

A porcentagem da categoria "não participação" é similar entre professores $(17,4 \%)$ e alunos (14,1\%). No entanto, o comportamento agressivo é percebido mais fortemente pelos professores $(13,9 \%)$ do que pelos alunos $(8,4 \%)$.

A própria comparação entre a posição de rejeição segundo a ótica dos professores e das crianças (dos 23 casos de maior incidência de rejeição) aponta para a concordância dos resultados, tanto entre as crianças como entre os professores. Uma vez que as classificações apontam para comportamentos externalizados, constata-se que os mesmos devem ocorrer nas crianças alvo de rejeição, em índice significativo mesmo para diferentes observadores, com distintos graus de relacionamento com as crianças - alvo.

No geral, conclui-se que as crianças que obtiveram altos índices de rejeição entre os pares, denotaram escore elevado também segundo a percepção dos professores.

\section{PASSA A BOLA}

O Quadro 2 visualiza as categorias de escolha, seguidas pela sedimentação de suas definições e das justificativas fornecidas pelas crianças. 
Quadro 2: Definição dos indicadores de escolha

\begin{tabular}{|c|c|c|}
\hline $\begin{array}{c}\text { CATEGORIAS DE } \\
\text { ESCOLHA }\end{array}$ & $\begin{array}{l}\text { DEFINIÇÕES } \\
\text { OPERACIONAIS }\end{array}$ & $\begin{array}{c}\text { JUSTIFICATIVAS } \\
\text { (fornecidas pelas } \\
\text { crianças) }\end{array}$ \\
\hline $\begin{array}{l}\text { 1. Qualidades } \\
\text { Pessoais }\end{array}$ & $\begin{array}{l}\text { Atributos positivos que } \\
\text { se delegam às pessoas } \\
\text { de modo bastante } \\
\text { subjetivo, valorativo, } \\
\text { sem esclarecimento do } \\
\text { comportamento } \\
\text { específico do sujeito } \\
\text { observado. }\end{array}$ & $\begin{array}{l}\text { Amigo, sincero, amável, } \\
\text { simpático, amoroso. }\end{array}$ \\
\hline $\begin{array}{l}\text { 2. Comportamentos } \\
\text { Operacionalizáveis }\end{array}$ & $\begin{array}{l}\text { Comportamentos } \\
\text { operacionalizados, que } \\
\text { descrevem atividades } \\
\text { do sujeito. } \\
\text { Atitudes que } \\
\text { transmitem bom } \\
\text { humor, que } \\
\text { descontraem o } \\
\text { ambiente. }\end{array}$ & $\begin{array}{l}\text { Engraçado, não leva as } \\
\text { coisas a mal, divertido, } \\
\text { brincalhão. }\end{array}$ \\
\hline 2B. Participação & $\begin{array}{l}\text { Atitudes de inclusão, } \\
\text { de envolvimento ativo } \\
\text { e participativo no } \\
\text { contexto. }\end{array}$ & $\begin{array}{l}\text { Brinca comigo, joga } \\
\text { comigo, ajuda. }\end{array}$ \\
\hline 2C. Não-agressão & $\begin{array}{l}\text { Condutas não } \\
\text { agressivas e de } \\
\text { respeito em relação } \\
\text { aos demais. }\end{array}$ & Não briga, me respeita. \\
\hline $\begin{array}{l}\text { 3. Habilidades } \\
\text { Acadêmicas, Motoras } \\
\text { e Intelectuais }\end{array}$ & $\begin{array}{l}\text { Presença de } \\
\text { habilidades relativas à } \\
\text { área acadêmica, } \\
\text { intelectual ou motora. }\end{array}$ & $\begin{array}{l}\text { Esperto, sabe jogar, } \\
\text { bom jogador, } \\
\text { inteligente. }\end{array}$ \\
\hline
\end{tabular}

A Tabela 2 apresenta as comparações entre as escolhas feitas ao seu próprio sexo, ao sexo oposto e no total geral.

Tabela 2: Escolha em relação ao próprio sexo e ao sexo oposto - total geral 


\begin{tabular}{|c|c|c|c|c|c|c|}
\hline \multirow{2}{*}{$\begin{array}{l}\text { INDICADORES DE } \\
\text { ESCOLHA }\end{array}$} & \multicolumn{2}{|c|}{ MASCULINO } & \multicolumn{2}{|c|}{ FEMININO } & \multicolumn{2}{|c|}{ TOTAL } \\
\hline & № & $\%$ & № & $\%$ & № & $\%$ \\
\hline MASCULINO & 28 & 96,6 & 05 & 10,6 & 33 & 43,4 \\
\hline - Qualidades Pessoais & 08 & 27,6 & 02 & 4,3 & 10 & 13,2 \\
\hline $\begin{array}{l}\text { - Comportamentos } \\
\text { Operacionalizáveis }\end{array}$ & 15 & 51,7 & 03 & 6,3 & 18 & 23,6 \\
\hline - Bom Humor & 06 & 20,7 & 01 & 2,1 & 07 & 9,2 \\
\hline - Participação & 08 & 27,6 & 01 & 2,1 & 09 & 11,8 \\
\hline - Não-Agressão & 01 & 3,4 & 01 & 2,1 & 02 & 2,6 \\
\hline $\begin{array}{l}\text { - Habilidades } \\
\text { Acadêmicas e Motoras }\end{array}$ & 05 & 17,3 & - & - & 05 & 6,6 \\
\hline FEMININO & 01 & 3,4 & 42 & 89,4 & 43 & 56,6 \\
\hline - Qualidades Pessoais & - & - & 25 & 53,2 & 25 & 32,9 \\
\hline $\begin{array}{l}\text { - Comportamentos } \\
\text { Operacionalizáveis }\end{array}$ & 01 & 3,4 & 14 & 29,8 & 15 & 19,8 \\
\hline - Bom Humor & 01 & 3,4 & 08 & 17,0 & 09 & 11,9 \\
\hline - Participação & - & - & 05 & 10,7 & 05 & 6,6 \\
\hline • Não-Agressão & - & - & 01 & 2,1 & 01 & 1,3 \\
\hline $\begin{array}{l}\text { - Habilidades } \\
\text { Acadêmicas e Motoras }\end{array}$ & - & - & 03 & 6,4 & 03 & 3,9 \\
\hline TOTAL & 29 & 100,0 & 47 & 100,0 & 76 & 100,0 \\
\hline
\end{tabular}

Geral $\rightarrow \chi_{\text {calc }}^{2}=50,44 ; p<0,00001$

Masculino $\rightarrow$ Masculino $x$ Feminino $\rightarrow$ Feminino: $z=0,695 ; p=0,487$

Masculino $\rightarrow$ Masculino $x$ Masculino $\rightarrow$ Feminino: $z=7,110 ; p<0,0001$

Feminino $\rightarrow$ Masculino $x$ Feminino $\rightarrow$ Feminino: $z=7,110 ; p<0,0001$

Vale ressaltar que meninos e meninas escolhem principalmente devido a algum comportamento operacionalizável, como bom humor, participação ou não-agressão $(23,6 \%)$ e depois por qualidades pessoais, que não viabilizam uma operacionalização objetiva $(13,2 \%)$.

De modo geral, os meninos escolhem os meninos $(96,6 \%)(p=0,0001)$ principalmente pelas qualidades pessoais $(27,6 \%)$ e pela participação $(27,6 \%)$.

A Figura 4 realiza comparação entre os três indicadores.

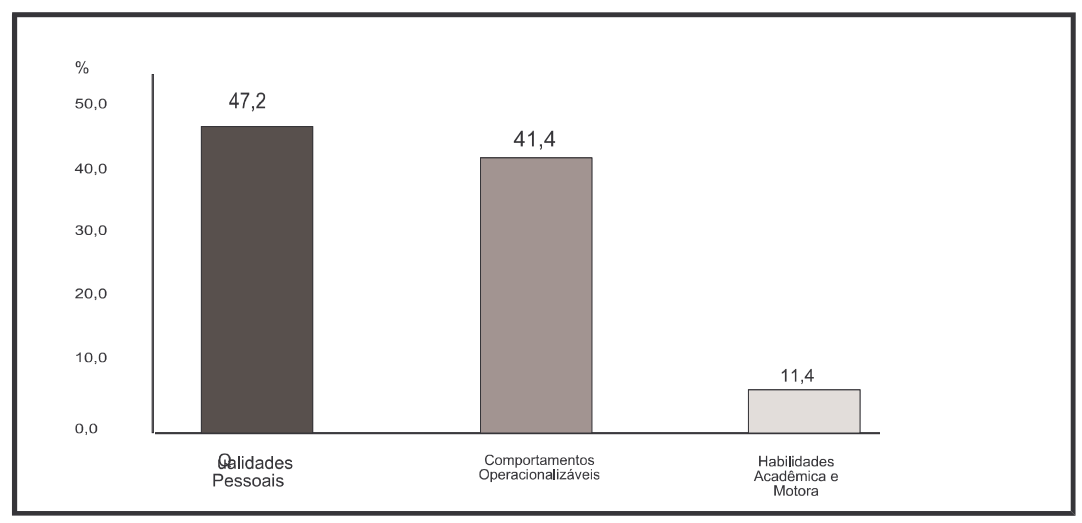

Figura 4: Comparação dos indicadores de escolha - total.

Conforme se pode detectar através desta representação, escolhem-se colegas, principalmente por qualidades pessoais $(47,2 \%)$ - designações mais subjetivas - e por 
comportamentos operacionalizáveis $(41,4 \%)$ - designações mais objetivas, muito mais do que por habilidades acadêmicas e motoras $(11,4 \%)$.

\section{CONCLUSÃO}

Os dados desta pesquisa revelam que os comportamentos que, quando presentes, podem levar a criança a ser rejeitada pelos pares estão associados principalmente a autoritarismo, conduta perturbadora, agressiva e de não participação, e estas classes comportamentais são designadas de "indicadores de rejeição".

$\mathrm{Na}$ direção oposta, a presente pesquisa aponta um rol de comportamentos que levam as crianças a aproximarem outras de si. A esta classe de comportamentos, denomina-se "indicadores de escolha". Estes últimos referem-se justamente a condutas pró-sociais que vêm a neutralizar comportamentos inadequados. Sendo assim, crianças escolhem seus pares segundo comportamentos operacionalizáveis de bom humor, participação, não-agressão; qualidades pessoais favoráveis que estes apresentem, como ser bondoso, amigável, simpático, ser possuidor de habilidades acadêmicas, motoras e intelectuais, necessárias à atividade em questão. Deste modo, há estímulos que propiciam aproximação, enquanto outros acarretam afastamento.

O que faz as pessoas se aproximarem ou se afastarem, e que, por sua vez, caracteriza a escolha ou a rejeição entre os pares, encontra-se nas condutas favoráveis ou desfavoráveis que as crianças apresentam nas suas relações.

Ninguém nasce rejeitado, mas experimenta a rejeição nos seus relacionamentos, e isto é passível de mudança. A expectativa é de que as mudanças ocorram, o quanto antes na vida da criança para que este processo de rejeição não deixe suas marcas profundas a ponto de a criança vir a apresentar grandes dificuldades de adaptação socioafetiva em sua vida enquanto adolescente e adulto.

Detectando os comportamentos pró-sociais que facilitam a aceitação e o bom relacionamento entre as pessoas, estes podem ser utilizados quase como "antídotos" na redução ou prevenção dos comportamentos de risco para a delinqüência, a saber: agressividade, oposição, hiperatividade, entre outros.

Esta pesquisa evidencia que crianças, emitindo classes comportamentais consideradas "indicadores de rejeição" (autoritarismo, conduta perturbadora e agressividade), são aquelas que mais sofrem 0 afastamento dos seus pares. Por outro lado, crianças escolhidas, o são, justamente por apresentarem comportamentos pró-sociais.

Segundo Patterson, Reid e Dishion (1992), a família pode treinar a criança a condutas apropriadas ou inapropriadas e, passar a desenvolver um "padrão educativo". Os autores entendem por padrão educativo favorável, aquele que pressupõe comandos e solicitações claros, respostas positivas e ações cooperativas, conseqüências negativas para condutas inadequadas, envolvimento, monitoramento e disciplina.

Programas, como os propostos por Patterson, Reid e Dishion (1992) Arón e Milicic (1994) e Castillo (1999) podem representar algumas alternativas de auxílio, de caráter preventivo, para a criança vir a apresentar, na escola ou na família, formas mais adaptativas de convívio social. Constituem, portanto, uma contribuição para a prevenção da saúde mental.

A presente pesquisa espera, de algum modo, contribuir para este vasto campo que é o desenvolvimento social da criança e sensibilizar para novos estudos e intervenções de caráter psico-educativo e preventivo.

\section{REFERÊNCIAS BIBLIGRÁFICAS}

Adorno, T. W; Brunswick, E. F.; Levinson, D. J. \& Sanford, R. N. (1965). La personalidad autoritária. Buenos Aires: Editorial Proyección.

Ames, R.; Ames, C. \& Garrison, W. (1977). Children's causal ascriptions for positive and negative interpersonal outcomes. Psychological Reports, 41, 595-602.

Argyle, M. (1976). A interação social: Relações interpessoais e comportamento social (Trad. de Márcia Nunes). Rio de Janeiro: Zahar. 
Arón, A. M. \& Milicic, N. (1994). Programa de desenvolvimento de habilidades sociais (Trad. Jonas P. dos Santos). São Paulo: Editorial Psy II.

Asher, S. \& Dodge, K. A. (1986). Identifying children who are rejected by their peers. Developmental Psychology, 22, 444-449.

Asher, S.; Parkhurst, J.; Hymel, S. \& Williams, G. (1995). Peer rejection and loneliness in childhood. Em S. Asher \& J. Coie (Orgs.), Peer rejection in childhood (p. 253-273). New York: Cambridge University Press.

Asher, S. \& Coie, J. (1995). Peer rejection in childhood. New York: Cambridge University Press.

Briggs, D. C. (1986). Criança feliz: o desenvolvimento da autoconfiança. São Paulo: Martins Fontes.

Cassidy, J.; Kirsh, S.; Scolton, K. \& Parke, R. (1996). Attachment and representations of peer relationships. Developmental Psychology, 32, 892-904.

Castillo, G. (1999). Educação para a amizade (Trad. Roberto Martins). São Paulo. Quadrante.

Coie, J.; Dodge, K. \& Coppotelli, H. (1982). Dimensions and types of social status: a cross-age perspective. Developmental Psychology, 18, 557-570.

Coie, J.; Dodge, K. \& Kupersmidt, J. (1995). Peer group behavior and social status. Em S. Asher \& J. Coie (Orgs.), Peer rejection in childhood (p. 17-57). New York: Cambridge University Press.

Coie, J. \& Koeppl, G. (1995). Adapting intervention to the problems of aggressive and disruptive rejected children. Em S. Asher \& J. Coie (Orgs.), Peer rejection in childhood (p. 309-337). New York: Cambridge University Press.

Dodge, K. (1983). Behavioral and antecedents of peers social status. Child Development, 54, 1386-1399.

Dodge, K.; Schlundt, D.; Schocken J. \& Delugach, J. (1983). Social competence and children's sociometric status: the role of peer group entry strategies. Merill Palmer Quarterly, 29, 309-336.

Gomes da Silva, V. R. M. \& Sternadt, A. (1999). Levantamento inicial sobre procedimentos relativos a famílias em escolas públicas e particulares de Curitiba. UFPR. Projeto não publicado.

Gomes da Silva, V. R. M. (2000). Indicadores de rejeição em grupo de crianças. Dissertação de Mestrado, Universidade Federal do Paraná.

Gottmann, J.; Gonso, J. \& Rasmussen, B. (1975). Social interaction, social competence and friendship in children. Child Development, 46, 709-718.

Hartrup, W. \& Rubin, Z. (1986). Relationships and development. USA: Lawrence Erl Baum Associates Publishers.

Kazdin, A. E. \& Buela-Casal, G. (1998). Conduta Anti-social. Evaluación, tratamiento y prevención en la infancia y adolescencia. Madrid: Ediciones Pirâmide S.A.

Leite, D. M. (1981) Educação e relação interpessoais. Em M. Helena S. Patto (Org.), Introdução à Psicologia. São Paulo: T. A. Queiroz.

Lerner, R. M. \& Lerner, J. (1977). Effects of age, sex and physical attractiveness on child - peer - relations, academic performance and elementary school adjustment. Developmental psychology, 13, 585-590.

Lindgren, H. C. \& Byrne, D. (1982) Psicologia: personalidade e comportamento social. Rio de Janeiro: Livros Técnicos e Científicos Editora.

Llario, M. D. G., Cots, M. D. L. \& Casas, A. M. (1992). Comparación de dos programas para el entrenamiento de las habilidades sociales de los escolares rechazados y olvidados. Em T. Bonet (Org.), Problemas Psicológicos en la infancia. Programas de intervención. Valência: Promolibro Cinteco.

López, F. (1995). Desenvolvimento social e da personalidade. Em C. Coll; J. Palacios; Á.. Marchsi (Orgs.), Desenvolvimento psicológico e educação. Psicologia evolutiva. Porto Alegre: Artes Médicas.

Mailhiot, G. B. (1991). Dinâmica e Gênese dos Grupos (7ª̣ ed.). São Paulo: Livraria Duas Cidades.

Maluf, M. R. (1991). As causas do fracasso escolar na perspectiva de professores e alunos de uma escola de $1^{\circ}$ grau. Psic. Teoria e Pesquisa, 7(3), 263-271.

Masters, J. \& Furman, W. (1981). Popularity, individual friendship selection and specific peer interaction among children. Developmental Psychology, 17, 344 - 350.

Marturano, E. M.; Linhares, M. B. M. \& Parreira, V. L. C. (1983). Problemas emocionais e comportamentais associados a dificuldades na aprendizagem escolar. Medicina de Ribeirão Preto, 26(2), p. 161-175.

Patterson, G. R.; Reid, J. B. \& Dishion, T. J. (1992). Antisocial boys. EUA: Castalia Publishing Company.

Peery, J. C. (1979). Popular, amiable, isolated, rejected: a reconceptualization of sociometric status in preschool children. Child Development, 50, 1231-1234. 
Price, J. \& Dodge, K. (1989). Peer's contributions to children's social maladjustment. Em T. Berndt \& G. Laad (Orgs.), Peer relationships in child development. USA: A. Wiley Interscience publication.

Putallaz, M. (1983). Predicting children's sociomentric status from their behavior. Child Development, 54, 14171426.

Putallaz, M. \& Gottman, J. (1981). Social skills and group acceptance. Em S. Asher \& J. Gottman (Org.), The development of children's friendships. USA: Cambridge University Press.

Putallaz, M. \& Wasserman, A. (1989). Children's naturalistic entry behavior and sociomentric status: a developmental perspective. Developmental Psychology, 25, 297-305.

Ross, A. (1979). Distúrbios psicológicos na infância. São Paulo: MC Graw Hill do Brasil Ltda.

Rubin, K. (1990). Peer relationships and social skills in child hood: an international perspective. Human Development, 33, 221-224.

Vosk, B.; Forehand, R.; Parker, J. \& Richard, K. (1982). A multimethod comparison of popular and unpopular children. Developmental Psychology, 4, 571-575. 